cromoglycate with isoprenaline, when this combined preparation only serves to confuse both patient and doctor and leads to the incorrect prophylactic use of Intal itself?

In our asthma clinic we have seen many patients who have been led to believe that the immediate relief of wheeze, caused by the isoprenaline in the inhaled powder of Intal-Co, is the disired therapeutic effect. The Spinhaler is then used as a simple bronchodilator, irregularly and intermittently, and the prophylactic effect of the cromoglycate itself is lost. Not only is this a wasteful way of taking isoprenaline, but many of these patients whose asthma is uncontrolled by such intermittent usage of Intal respond to this substance when they are instructed in its correct use by the Spinhaler, which is regularly throughout the day, regardless of whether wheeze is present or not.

Most patients taking Intal regularly do not require isoprenaline with it; but the few that do get transient wheeze or coughing, associated with the inhalation of the powder, can easily be given bronchodilator aerosol in addition to their Spinhaler. It is then much easier for doctors to tell patients to use the Spinhaler regularly, but to use the "puffer" only when wheezing or cough occurs.

We hope that the future of Intal itself, which we find to be of real benefit in a selected type of asthmatic patients, will not be prejudiced by the continued availability of this combination with isoprenaline marketed as Intal-Co.-We are, etc.,

\section{PHILIP HUGH-JONES.}

M. C. WINTERTON

King's College Hospital,
London S.E.5.

A. SMITH

\section{Medical Students and Smoking}

SIR,-Dr. J. P. Anderson (10 October, p. 120) rightly stresses the urgent need for more effective medical education concerning cigarette smoking-a habit which Sir George Godber describes in his annual report as the greatest avoidable menace to health in Britain today. ${ }^{1}$

There are two important reasons why all medical students (as well as their teachers) should see clearly on this matter. The first is that doctors who smoke are much less likely to help their patients to stop than those who do not, and many patients will in fact respond to their doctor's advice to stop smoking. Secondly, medical schools will produce more doctors who will survive to practise medicine till retirement age if their graduates do not smoke cigarettes. The Royal Commission on Medical Education ${ }^{2}$ recommends that the number of practising doctors should increase from 62,500 in 1965 to 119,800 in 1995. Since doctors who smoke cigarettes have a $28 \%$ higher mortality than those who do not $^{3}$ considerably more medical graduates will be needed to achieve this objective if some doctors continue to smoke.

The academic board of this medical school has resolved that all our students should be fully aware of the problem of cigarette smoking and health. It is considered of such importance that all preclinical students receive information and are able to discuss this matter on their first day of entry to the school. Clearly this is a matter which every medical school should take most seriously. - I am, etc.,

\section{KeIth Ball.}

Middlesex Hospital Medical School, London $\mathbb{W} .1$.

\section{REFERENCES}

Chief Medical Officer of the Department of Health and Social Security, Annual Report for the Year 1969 , on the State of the

H.M.S.O., 1970, p. 9. Royal Commission on Medical Education, 1965-68 Report, Cmnd. 3569, London, H.M.S.O. 1968.
Doll, R., and Hill, A. B., British Medical łournal $1964,1,1399$.

\section{Depression and Oral Contraception}

SIR,-I think the otherwise very careful and useful study of Dr. Brenda N. Herzberg and others (17 October, p. 142) is vulnerable to one very serious criticism. The control group was made up almost wholly of users of the diaphragm method of contraception.

I think it is the experience of most general practitioners that, at least among working-class women, the diaphragm is rejected or soon discarded by the majority. Even those referred for a diaphragm are highly selected, and those who continue to use it are probably very highly selected.

One would anticipate that the successful diaphragm users would be of more stable temperament than oral contraceptive users, and indeed this has been my experience. If so the conclusions reached by this study are not valid.-I am, etc.,

Port Talbot,
Glamorgan

J. TUdOR HART.

SIR,-Dr. Brenda Herzberg and others (17 October, p. 142) have reported that $6.6 \%$ of women taking several oral contraceptives were more severely depressed than any of the control group. They tested three oral contraceptives in sufficient numbers to assess their depressive effect. These were Gynovlar, Lyndiol 2.5, and Ovulen. All three are predominantly progestogenic with a similar effect on the endometrium and breakthrough bleeding incidences of 3-4\%. It is unlikely therefore that this study would show the effect of variations of hormone balance on depression. They did find a significantly higher incidence of depressive symptoms with Lyndiol 2.5 compared with the other oral contraceptive and control groups.

In a trial by the Council for the Investigation of Fertility Control ${ }^{2}$ we found that of 34 consecutive women completing 576 cycles on Lyndiol 2.5 in a three year period $26 \%$ had depressive symptoms, compared with $13 \%$ of 30 women completing 629 cycles on Ovulen. With these pills the highest endometrial monoamine oxidase activity occurred later than in a normal cycle, which may account for the cyclic variations in depth of depression reported by Dr. Herzberg and others, but there was more monoamine oxidase activity during the earlier part of the cycle than was found in control cycles. Gynovlar was not assessed in this trial.

After testing 26 oral contraceptives in sufficient numbers for individual assessment, we concluded that the depressive effect of an oral contraceptive depends not only on its progestogenic effect as estimated by the incidence of breakthrough bleeding and endometrial changes, but also on the dose and type of oestrogen. The average incidence of depression for nine intermediate compounds with 0.075 or $0.05 \mathrm{mg}$. oestrogen (mostly ethinyl oestradiol) was $23 \%$, compared with $10 \%$ for seven intermediate compounds with $0.1 \mathrm{mg}$. mestranol. The incidence of depressive symptoms for all pills tested in our study ranged from $2 \%$ to over $35 \%$. It seems reasonable to discontinue oral contraceptives before depression becomes too severe in an individual patient.-I am, etc.,

Ellen C. G. GRANT.

New Malden, Surrey.

REPERENCES

1 British Medical foumal, 1969, 4, 789. Medical fournai, 1968, 3ryse-Davies, J., British

\section{Allegations of Negligence}

SIR,-The answer to Dr. R. C. R. Conner's question (24 October, p. 242) whether an allegation of negligence has ever been made against a pathologist is "yes." In recent years the Medical Protection Society has dealt with cases of mismatched blood transfusions, incorrect haemoglobin estimations, and failure to give appropriate priority to urgent communications about a patient.

These facts do not make a compelling case for granting preferential subscription rates to pathologists, but other allegedly "low-risk" groups have made similar representations and the problem has been referred to the joint co-ordinating committee of the three defence societies.-I am, etc.,

Herbert Constable. Secretary,

London w.1. Medical Protection Society.

\section{Toxocariasis}

SIR,-Dr. C. B. Vaughan (17 October, p. 179) mentions Toxocara canis as the cause of cutaneous larva migrans. I feel sure he has incriminated the wrong species as Toxocara canis is the cause of visceral larva migrans.

Cutaneous larva migrans is usually caused by hookworm larvae, particularly Ancylostoma braziliense. These worms can penetrate intact skin and hence they easily infect people in contact with contaminated situations such as mentioned in Dr. Vaughan's letter.-I am, etc.

Macclesfield,

W. A. BRADLEY.

Cheshire.

\section{Myocardial Infarction and the G.P.}

SIR,-My plan for coronary "first aid" with regard to our local geography and summer traffic thrombosis is:

(1) Instant analgesia with intravenous morphine $10 \mathrm{mg}$. with $50 \mathrm{mg}$. promethazine.

(2) A nose-bag of oxygen.

(3) A regular pulse gets 1 g. procaineamide orally, as the Boston study (14 March, p. 646) conclusively proved it a 